\title{
Ecomorphology of the eyes and skull in zooplanktivorous labrid fishes
}

\author{
L. Schmitz $\cdot$ P. C. Wainwright
}

Received: 7 August 2010/Accepted: 19 December 2010/Published online: 8 January 2011

(C) The Author(s) 2011. This article is published with open access at Springerlink.com

\begin{abstract}
Zooplanktivory is one of the most distinct trophic niches in coral reef fishes, and a number of skull traits are widely recognized as being adaptations for feeding in midwater on small planktonic prey. Previous studies have concluded that zooplanktivores have larger eyes for sharper visual acuity, reduced mouth structures to match small prey sizes, and longer gill rakers to help retain captured prey. We tested these three traditional hypotheses plus two novel adaptive hypotheses in labrids, a clade of very diverse coral reef fishes that show multiple independent evolutionary origins of zooplanktivory. Using phylogenetic comparative methods with a data set from 21 species, we failed to find larger eyes in three independent transitions to zooplanktivory. Instead, an impression of large eyes may be caused by a size reduction of the anterior facial region. However, two zooplanktivores (Clepticus parrae and Halichoeres pictus) possess several features interpreted as adaptations to zooplankton feeding, namely large lens diameters relative to eye axial length, round pupil shape, and long gill rakers. The third zooplanktivore in our analysis, Cirrhilabrus solorensis, lacks all above features. It remains unclear whether Cirrhilabrus shows optical specializations for capturing planktonic prey. Our results support the prediction that increased visual acuity is adaptive for zooplanktivory, but in labrids increases in eye size are apparently not part of the evolutionary response.
\end{abstract}

Communicated by Biology Editor Prof. Philip Munday

L. Schmitz $(\bowtie)$ · P. C. Wainwright

Department of Evolution and Ecology, University of California,

Davis, CA 95616, USA

e-mail: 1schmitz@ucdavis.edu

P. C. Wainwright

Center for Population Biology, University of California,

Davis, CA 95616, USA
Keywords Zooplanktivory · Labrids · Visual acuity · Eyeball morphology $\cdot$ Adaptation $\cdot$ Coral reef fish

\section{Introduction}

Zooplankton feeding is one of the most distinct and repeatedly evolved trophic niches observed in reef fishes. While virtually all reef fish species begin life feeding on zooplankton, evolutionary transitions to this diet in the adult have occurred in at least 10 families of reef fish making this a rich system for the study of convergent evolution (Wainwright and Bellwood 2002). The shift to midwater zooplanktivory is thought to generate specific requirements for swimming performance (higher sustained swimming speed), vision (detection of small, partly transparent, drifting prey), and feeding mode (capture of small, unattached prey) (Hobson 1991; Wainwright and Bellwood 2002). These requirements are thought to be met with a series of morphological adaptations (Davis and Birdsong 1973; Hobson 1991; Wainwright and Bellwood 2002). Both the morphology of the feeding apparatus (Barel 1982; Motta 1988; Wainwright and Richard 1995; Wainwright et al. 2004; Cooper and Westneat 2009) and locomotion (Hobson and Chess 1976, 1978; Hobson 1991; Langerhans et al. 2003; Wainwright et al. 2002) have received considerable attention. Studies of the visual system in zooplanktivores are mainly confined to comparisons of eye size (Davis and Birdsong 1973; McPhail 1984; Goatley and Bellwood 2009).

The extensive literature on zooplanktivory has produced a clear sense of the common features associated with transitions to this specialized diet. One of the classic findings is that zooplanktivores have larger eyes than other fish (Fryer and Iles 1972; Davis and Birdsong 1973; Dullemeijer and 
Barel 1977; McPhail 1984; Strauss 1984; Baumgartner et al. 1988; Pankhurst 1989; Hart and Gill 1994; Wainwright and Bellwood 2002; Kassam et al. 2003; Hulsey et al. 2007; Cooper and Westneat 2009; Goatley and Bellwood 2009). The functional reasoning for this is provided by predictions from physiological optics. A larger eye can house a larger lens with longer focal length, which improves visual acuity (Lythgoe 1979; Land 1981; Fernald 1990). Zooplanktivorous fish are highly visual foragers, which select and pick individual prey items in the water column above coral reefs. The detection of planktonic prey is a difficult visual task, because of the small size of zooplankton $(<3 \mathrm{~mm}$; Hobson $1991)$ and the low contrast between prey and visual background (Douglas and Hawryshyn 1990; Loew and McFarland 1990; Johnsen 2001). High visual acuity increases the probability of detecting prey and improves feeding rate and is therefore directly related to fitness. Since visual acuity scales with eye size (Hairston et al. 1982; Kiltie 2000), large eyes may represent an adaptation to zooplanktivory. This idea is deeply embedded in the literature on the ecology and morphology of fishes.

Previous studies have found that zooplanktivorous reef fish substantially modify their feeding apparatus, typically showing a reduction of feeding structures, especially mouth and adductor muscle size (Wainwright 1988; Wainwright and Bellwood 2002; Wainwright et al. 2004; Cooper and Westneat 2009). The length and density of gill rakers influences the retention of prey particles in the oral cavity (Magnuson and Heitz 1971; Drenner et al. 1984; Schluter 1993; Robinson and Parsons 2002; Ingram and Shurin 2009). Small prey such as zooplankton may escape after capture, and thus, long and closely spaced gill rakers that function like a sieve are considered an adaptation to zooplanktivory. As a cautionary note, some authors reported deviations from the general pattern (Motta 1988; Langeland and Nøst 1995), yet all in all, gill raker length and density are both considered to be frequently associated with zooplanktivory.

In this study, we analyze changes in eye, skull, and gill raker morphology associated with the evolution of zooplanktivory in Labridae (Teleostei, Perciformes). Labrid fishes are a morphologically, taxonomically, and ecologically very diverse clade of reef fish (Parenti and Randall 2000; Wainwright et al. 2004; Cowman et al. 2009). The phylogeny of labrid fishes is highly resolved (Westneat and Alfaro 2005; Alfaro et al. 2009; Cowman et al. 2009; Kazancioğlu et al. 2009), which makes this an attractive system for testing ecomorphological hypotheses in a phylogenetic framework. We test for three classic ecomorphological correlates of zooplanktivory and introduce two novel predictions. We test whether zooplanktivorous fish show specializations of eye morphology: do they have relatively large eyes, large lenses, or other features of eye shape that may enhance visual acuity? We also ask whether zooplanktivores have smaller oral structures, specifically compared to the size of their orbit. Finally, we ask whether zooplanktivorous labrids have longer and more densely packed gill rakers than non-planktivores.

\section{Materials and methods}

Morphological proxies of visual acuity

Visual acuity is an integrated result of the optics of the refractive apparatus, structure and composition of the retina, chemistry of visual pigments, and neural processing in the retina and brain (Hung and Ciuffreda 2002). A simplified proxy for acuity is resolving power, an index derived from retinal and optical features. The resolving power of a camera-type eye describes the ability to discriminate fine detail in the visual environment (Lythgoe 1979; Miller 1979; Land 1981; Land and Nilsson 2002; Schmitz 2009). Formally, the resolving power of the eye is defined as

$$
v=\mathrm{f} / 2 \times \mathrm{s} \times(180 / \pi) \text { [cycles/degree] (Land 1981), }
$$

where $f$ is the first focal length, i.e., the distance from the nodal point to the image, and $\mathrm{s}$ is the photoreceptor separation.

Visual acuity can be improved by two mechanisms, assuming that neural processes in the retina and visual cortex remain the same. First, a longer focal length produces a larger retinal image (Hughes 1977; Land 1981; Schmitz and Motani 2010), which in turn improves discrimination of fine detail. Second, smaller photoreceptors and denser packing enhance resolving power. Thus, one mechanism to improve resolving power requires changes at the macroscopic level (focal length), while the other mechanism requires modifications at the microscopic level (photoreceptors). In this study, we focus on visual acuity at the macroscopic level.

The determinants of focal length, i.e., the components of the refractive apparatus, are the key to understanding macroscopic mechanisms for improved resolving power. The focal length of teleost eyes is determined by the radii of curvature of the front and back surface of the lens and its refractive index (Fernald 1990).

Larger radii of curvature equate to longer focal length, assuming the refractive index remains constant (Land and Nilsson 2002). Modifications of the radii of curvature to increase focal length include two possibilities. One is to make the lens bigger, maintaining its spherical shape. Either the entire eyeball, including lens, is scaled up isometrically, or the lens is enlarged independently, but the eyeball size is constant or increases at a slower rate. For 
example, it is possible that the lens is scaled up while axial length remains the same, i.e., the size of the lens is maximized for a given axial length. In this scenario, the lens would have to be moved further toward the cornea in order to accommodate the longer focal length and maintain emmetropia. The other possibility is to flatten the front and back surfaces of the lens making it more elliptical, a feature rare in teleosts (Fernald 1990; Sivak 1990; Kröger et al. 2009).

\section{Species selection}

The Labridae contain approximately 600 species with a high diversity of ecological and morphological specializations (Parenti and Randall 2000; Wainwright et al. 2004; Cowman et al. 2009). Labrids are a promising group for studying phenotypic adaptations and evolution of eye morphology with respect to zooplanktivory for two reasons. First, the phylogenetic relationships among labrid species are reasonably well understood (Westneat and Alfaro 2005; Cowman et al. 2009; Kazancioğlu et al. 2009) allowing examination of trait evolution in association with transitions to zooplanktivory to be made among very close relatives. Second, several independent origins of zooplanktivory have been identified in the Labridae (Wainwright and Bellwood 2002; Wainwright et al. 2004; Westneat et al. 2005; Cowman et al. 2009), and we sampled species that represent three of them: Clepticus parrae, Cirrhilabrus solorensis, and Halichoeres pictus (Fig. 1).

The other 18 labrid species in our dataset were chosen to capture a broad range of labrid diversity: most are benthic foragers that feed on invertebrates, but included are almost the entire diet spectrum found in the Labridae (Randall 1967; Westneat 1995; Wainwright et al. 2004; Westneat and Alfaro 2005; Cowman et al. 2009). Two of the species specialize on crustacean ectoparasites and fish mucus
Fig. 1 Phylogeny of the 21 labrid species included in this study (modified from Kazancioğlu et al. 2009), with three independent origins of zooplanktivory. The schematic drawings illustrate the three zooplanktivores and their closest included relatives: Clepticus parrae (cp) and Bodianus mesothorax (bm), Halichoeres pictus (hp) and Halichoeres bivittatus (hb), Cirrhilabrus solorensis (cs), and Pseudocheilinus evanidus (pe). The star symbol signifies zooplanktivores

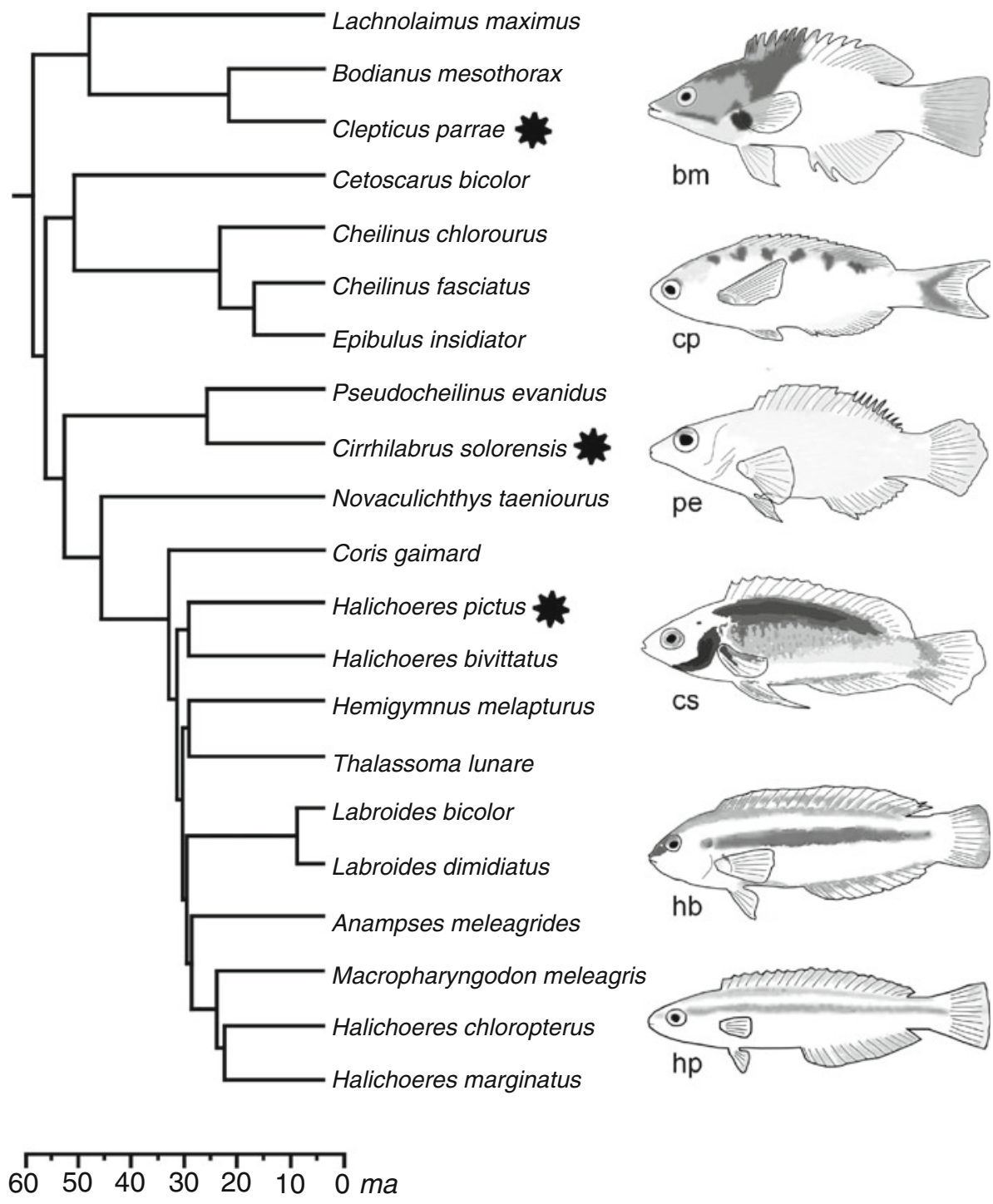


(Labroides bicolor and L. dimidiatus), and one species feeds on small fish and crustaceans (Epibulus insidiator). In order to achieve phylogenetically meaningful comparisons, we sampled species that are phylogenetically proximate to the zooplanktivores in our study, i.e., Bodianus mesothorax as sistertaxon to $C$. parrae, Pseudocheilinus evanidus as sistertaxon to $C$. solorensis, and Halichoeres bivittatus as sistertaxon to H. pictus (Fig. 1). Furthermore, representative species of most major subclades within Labridae are present (Hypsigenyines, Scarines, Cheilines, Pseudocheilines, Novaculines, and Julidines). The species sampling allows comparisons of zooplanktivores to close relatives and broader comparison within labrids.

Specimens, measurements, and procedures

We included 21 species of Labridae with a total number of 141 specimens (1-29 individuals per species) for eye morphometrics (Table 1). The size range across individuals is $44-255 \mathrm{~mm}$ standard length. The examinations of head proportions and gill raker morphology were largely based on the same specimens, with some minor deviations. For head size and proportions (Table 2), we included 57 specimens of the same 21 species (1-6 individuals per species). For gill raker morphology (Table 3), we included the same 21 species, with a total number of 40 specimens, (1-4 individuals per species), with a similar size range. All specimens were large juveniles or adults.

We dissected all specimens shortly after euthanizing them with an overdose of MS-222. We measured body weight on a digital scale with 0.05 -g accuracy. As additional proxies for body size, we measured standard length, body depth (at the level just anterior to the dorsal fin), and body width (at the level of the opercula) with dial calipers.

Next, we carefully excised the left eyeball, removed attached ocular muscles, and cut the optic nerve close to the sclera. We measured eyeball diameter, axial length, and the largest and smallest pupil diameter (Fig. 2) with a binocular stereomicroscope equipped with an optical micrometer. Then, we removed the iris and cornea, extracted the lens from the eye, and measured the equatorial diameter of the lens (Fig. 2). We repeated this procedure for the right eye.

Fish specimens were subsequently preserved in formalin and then cleared and stained. We quantified skull size and proportions with three different measures. Overall skull size is the area of the triangle defined by the tip of premaxilla, top of supraoccipital, and the posterior end of the

Table 1 Measurements of eye morphology

\begin{tabular}{|c|c|c|c|c|c|c|c|c|c|c|c|c|c|c|c|}
\hline Species & $\mathrm{n}$ & BW & sd & SL & sd & ED & sd & $\mathrm{AL}$ & sd & PD1 & sd & PD2 & sd & LD & sd \\
\hline Anampses meleagrides & 1 & 7.55 & - & 77.00 & - & 5.07 & - & 3.62 & - & 2.29 & - & 2.05 & - & 1.93 & - \\
\hline Bodianus mesothorax & 9 & 6.37 & 3.66 & 64.80 & 13.35 & 6.11 & 0.81 & 4.53 & 0.57 & 3.20 & 0.35 & 2.55 & 0.29 & 2.38 & 0.38 \\
\hline Cetoscarus bicolor & 3 & 11.87 & 8.78 & 80.67 & 21.01 & 6.80 & 1.07 & 5.24 & 0.94 & 2.88 & 0.45 & 2.54 & 0.36 & 2.37 & 0.41 \\
\hline Cheilinus chlorourus & 1 & 22.55 & - & 86.00 & - & 7.70 & - & 5.95 & - & 3.33 & - & 2.46 & - & 2.66 & - \\
\hline Cheilinus fasciatus & 1 & 29.10 & - & 94.00 & - & 7.78 & - & 6.11 & - & 3.33 & - & 2.94 & - & 2.82 & - \\
\hline Cirrhilabrus solorensis & 8 & 4.54 & 0.81 & 57.29 & 2.71 & 4.78 & 0.11 & 3.72 & 0.15 & 2.15 & 0.16 & 1.81 & 0.11 & 1.80 & 0.10 \\
\hline Clepticus parrae & 25 & 42.99 & 46.17 & 102.30 & 53.02 & 7.20 & 2.58 & 4.95 & 1.79 & 3.37 & 1.14 & 3.09 & 1.06 & 2.91 & 1.03 \\
\hline Coris gaimard & 5 & 18.72 & 7.36 & 105.66 & 7.46 & 6.19 & 0.31 & 4.58 & 0.26 & 2.74 & 0.12 & 2.42 & 0.15 & 2.29 & 0.14 \\
\hline Epibulus insidiator & 1 & 15.05 & - & 81.00 & - & 6.19 & - & 4.52 & - & 2.72 & - & 2.24 & - & 2.17 & - \\
\hline Halichoeres bivittatus & 29 & 17.00 & 12.57 & 90.35 & 26.42 & 5.54 & 0.93 & 3.74 & 0.84 & 2.36 & 0.41 & 2.03 & 0.36 & 2.04 & 0.37 \\
\hline Halichoeres chloropterus & 3 & 2.42 & 1.09 & 51.33 & 8.22 & 4.18 & 0.36 & 3.17 & 0.36 & 1.72 & 0.24 & 1.37 & 0.16 & 1.48 & 0.24 \\
\hline Halichoeres marginatus & 1 & 11.35 & - & 82.00 & - & 5.08 & - & 3.73 & - & 2.46 & - & 2.22 & - & 1.85 & - \\
\hline Halichoeres pictus & 25 & 5.88 & 2.68 & 70.43 & 12.13 & 4.94 & 0.67 & 3.11 & 0.62 & 2.06 & 0.37 & 1.89 & 0.30 & 1.89 & 0.26 \\
\hline Hemigymnus melapturus & 3 & 6.75 & 5.30 & 57.63 & 17.56 & 4.95 & 0.67 & 3.70 & 0.63 & 2.43 & 0.36 & 2.26 & 0.46 & 1.95 & 0.32 \\
\hline Labroides bicolor & 3 & 1.67 & 0.38 & 44.79 & 2.54 & 3.23 & 0.10 & 2.37 & 0.04 & 1.66 & 0.08 & 1.54 & 0.06 & 1.27 & 0.04 \\
\hline Labroides dimidiatus & 3 & 1.50 & 0.50 & 46.83 & 4.81 & 3.15 & 0.19 & 2.40 & 0.08 & 1.44 & 0.21 & 1.40 & 0.17 & 1.21 & 0.08 \\
\hline Lachnolaimus maximus & 1 & 401.80 & - & 255.00 & - & 19.01 & - & 14.34 & - & 8.57 & - & 7.70 & - & 7.14 & - \\
\hline Macropharyngodon meleagris & 3 & 8.32 & 2.02 & 72.73 & 5.37 & 4.87 & 0.07 & 3.64 & 0.17 & 2.24 & 0.06 & 2.01 & 0.03 & 1.89 & 0.02 \\
\hline Novaculichthys taeniourus & 5 & 8.84 & 8.08 & 71.08 & 19.72 & 4.96 & 0.86 & 3.54 & 0.66 & 2.21 & 0.42 & 2.02 & 0.44 & 1.74 & 0.36 \\
\hline Pseudocheilinus evanidus & 8 & 3.03 & 1.41 & 48.71 & 7.53 & 4.27 & 0.47 & 3.29 & 0.40 & 2.10 & 0.24 & 1.63 & 0.21 & 1.60 & 0.18 \\
\hline Thallassoma lunare & 3 & 7.35 & 4.04 & 70.20 & 7.92 & 4.66 & 0.60 & 3.68 & 0.30 & 2.27 & 0.26 & 1.91 & 0.29 & 1.80 & 0.18 \\
\hline
\end{tabular}

$B W$ body weight, $A L$ axial length, $E D$ eye diameter, $L D$ lens diameter, $P D 1$ largest pupil diameter, $P D 2$ smallest pupil diameter, $s d$ standard deviation, $S L$ standard length. Also see Fig. 2

BW in $[\mathrm{g}]$, all other measurements in [mm] 


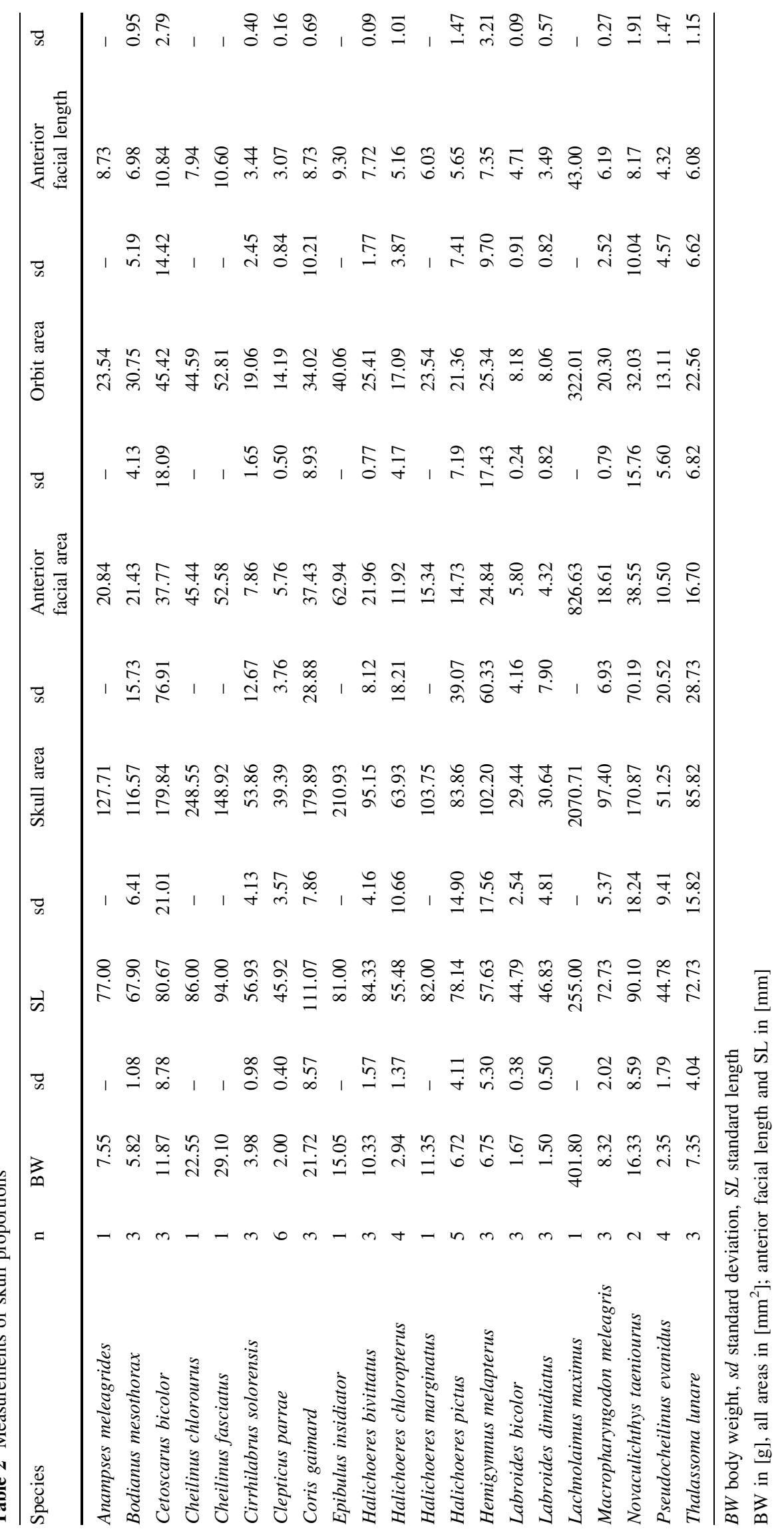


Table 3 Measurements of gill raker morphology

\begin{tabular}{|c|c|c|c|c|c|c|c|c|c|}
\hline Species & $\mathrm{n}$ & BW & $\mathrm{sd}$ & SL & $\mathrm{sd}$ & Length & $\mathrm{sd}$ & Spacing & $\mathrm{sd}$ \\
\hline Anampses meleagrides & 1 & 7.55 & - & 77.00 & - & 0.72 & - & 0.35 & - \\
\hline Bodianus mesothorax & 2 & 6.43 & 0.32 & 71.60 & 0.00 & 0.74 & 0.09 & 0.45 & 0.01 \\
\hline Cetoscarus bicolor & 2 & 15.40 & 8.91 & 91.00 & 15.56 & 0.85 & 0.14 & 0.36 & 0.06 \\
\hline Cheilinus chlorourus & 1 & 22.55 & - & 86.00 & - & 1.43 & - & 1.02 & - \\
\hline Cheilinus fasciatus & 1 & 29.10 & - & 94.00 & - & 0.99 & - & 0.87 & - \\
\hline Cirrhilabrus solorensis & 3 & 3.98 & 0.98 & 56.93 & 4.13 & 0.52 & 0.07 & 0.25 & 0.04 \\
\hline Clepticus parrae & 2 & 2.33 & 0.11 & 48.40 & 0.71 & 1.11 & 0.06 & 0.22 & 0.01 \\
\hline Coris gaimard & 2 & 26.60 & 1.91 & 113.40 & 2.55 & 1.35 & 0.06 & 0.73 & 0.07 \\
\hline Epibulus insidiator & 1 & 15.05 & - & 81.00 & - & 1.47 & - & 0.64 & - \\
\hline Halichoeres bivittatus & 3 & 10.33 & 1.57 & 84.33 & 4.16 & 0.83 & 0.07 & 0.45 & 0.02 \\
\hline Halichoeres chloropterus & 2 & 3.90 & 0.85 & 62.70 & 7.35 & 0.63 & 0.05 & 0.31 & 0.00 \\
\hline Halichoeres marginatus & 1 & 11.35 & - & 82.00 & - & 0.81 & - & 0.40 & - \\
\hline Halichoeres pictus & 4 & 5.01 & 1.77 & 72.03 & 6.83 & 0.94 & 0.07 & 0.31 & 0.01 \\
\hline Hemigymnus melapterus & 2 & 3.88 & 2.58 & 49.95 & 16.19 & 0.69 & 0.39 & 0.30 & 0.15 \\
\hline Labroides bicolor & 2 & 1.68 & 0.53 & 45.39 & 3.27 & 0.15 & 0.01 & 0.19 & 0.01 \\
\hline Labroides dimidiatus & 2 & 1.75 & 0.35 & 49.60 & 0.57 & 0.17 & 0.01 & 0.21 & 0.01 \\
\hline Lachnolaimus maximus & 1 & 401.80 & - & 255.00 & - & 2.90 & - & 2.22 & - \\
\hline Macropharyngodon meleagris & 2 & 8.95 & 2.40 & 73.70 & 7.21 & 0.53 & 0.07 & 0.32 & 0.00 \\
\hline Novaculichthys taeniourus & 2 & 16.33 & 8.59 & 90.10 & 18.24 & 1.91 & 0.43 & 0.73 & 0.10 \\
\hline Pseudocheilinus evanidus & 2 & 3.45 & 2.12 & 51.55 & 7.99 & 0.29 & 0.07 & 0.41 & 0.10 \\
\hline Thalassoma lunare & 2 & 9.58 & 1.73 & 81.55 & 5.87 & 0.63 & 0.01 & 0.35 & 0.01 \\
\hline
\end{tabular}

$B W$ body weight, $s d$ standard deviation, $S L$ standard length

BW in [g]; SL, length, and spacing in [mm]

interopercle. Anterior facial region is the area of the triangle defined by tip of premaxilla, anterior orbit margin, and articular-quadrate lower jaw joint. Anterior facial length is the distance from the anterior orbit margin to the tip of the premaxilla. These measurements capture the overall size of jaw structures and mouth (Wainwright et al. 2004). We estimated orbit size, a proxy for eye size (Schmitz 2009), as the area of the ellipse defined by anteroposterior and dorsoventral orbit diameter in cleared and stained specimens.

We removed the first gill arch and assessed size and density of the gill rakers by measuring the length of the three longest rakers on the ceratohyal. Density was measured by counting the number of gill rakers for a given distance along the ceratohyal. We measured the distance from anterior edge of the first gill raker to the anterior edge of the last raker in the segment.

Data analysis

We calculated the mean of measurements from the left and right eye for each individual and calculated species means. We then $\log _{10}$-transformed species averages. Our measure for body size was body mass. We analyzed data in a phylogenetically informed framework, because calculations of
Blomberg's K (Blomberg et al. 2003) indicated that the traits are phylogenetically patterned. We pruned the timecalibrated phylogeny of Kazancioğlu et al. (2009), so that the phylogeny contained only the species we included in this study (Fig. 1). Since $P$. evanidus and $C$. solorensis are not in the phylogenetic analysis of Kazancioğlu et al. (2009), we swapped these species for their close relatives Pseudocheilinus octotaenia and Cirrhilabrus lubbocki, respectively.

In order to describe the relationships between body size and eyeball dimensions, we followed two approaches. First, we described interspecific and ontogenetic scaling of eyeball diameter against body mass by calculating the regression slope with the standardized major axis (SMA) method. We chose SMA because both independent and dependent variable were measured with error, and SMA slope estimates are more efficient than major axis slope estimates (Warton et al. 2006). Calculations of SMA were implemented in the 'smatr' package (Warton and translated to $\mathrm{R}$ by Ormerod 2007) in R 2.11.1. Second, we calculated independent contrasts of the variables (Felsenstein 1985) with the 'ape' package (Paradis et al. 2004) in R 2.11.1 (R Development Core Team 2010). Then, we regressed the dependent variables using SMA and forced the y-intercept to be zero. Furthermore, we explored eye morphology with 


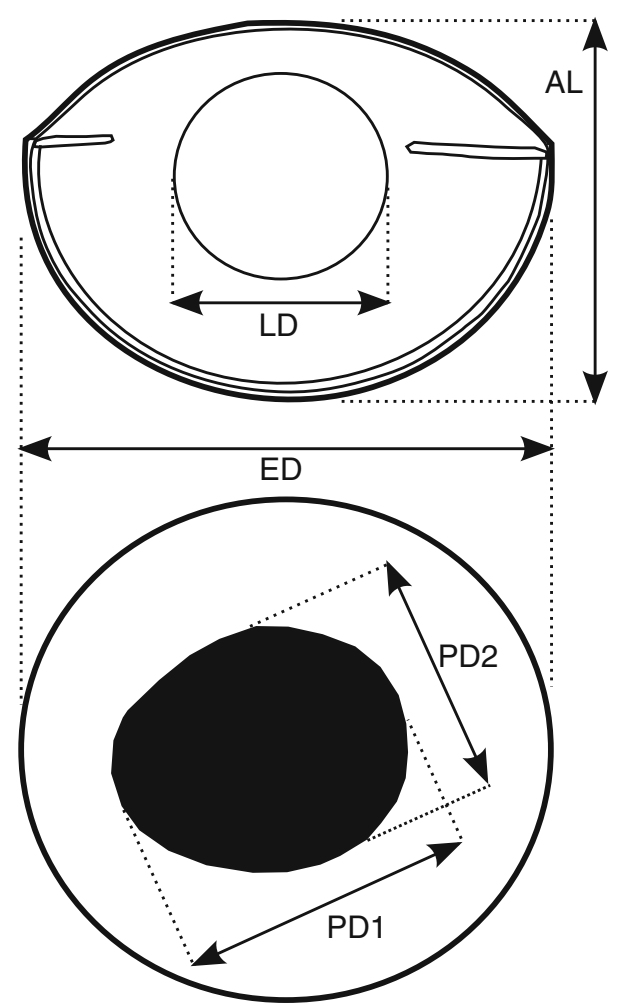

Fig. 2 Simplified drawings of a teleost eyeball illustrating morphological measurements in horizontal cross section (a) and lateral view (b). $A L$ axial length, $E D$ eyeball diameter, $L D$ horizontal lens diameter, $P D 1$ largest pupil diameter, $P D 2$ smallest pupil diameter

a phylogenetically informed principal component analysis (Revell 2009) to facilitate the identification of other possible features associated with zooplanktivory. Calculations were implemented in R 2.11.1.

For most subsequent analyses, we were interested in the relative size of the traits. We used size-corrected trait dimensions that accounted for the phylogenetic correlation within our data (Revell 2009). We calculated least-square residuals of eye diameter, gill raker length, and gill raker density on body size in order to test whether zooplanktivorous labrid fishes have larger eyes, and longer and more densely packed gill rakers compared to body size. To test whether zooplanktivorous labrids have a larger lens for given axial length, we calculated residuals of lens diameter on axial length. Finally, we calculated residuals of skull area, anterior facial area, and anterior facial length on orbit area in order to test whether zooplanktivorous labrids have smaller skull features compared to their orbit size. This would make the eyes appear larger.

Residuals alone are insufficient to detect the adaptive significance of morphological features, since they are still phylogeny-dependent. As we were interested in evolutionary changes that happened along the last branch segment leading to a zooplanktivorous species, we approximated evolutionary changes along branch segments by calculating point estimates of the rate of morphological evolution. For each trait (relative eyeball diameter, relative lens diameter, scores on principal components 2 and 3, relative skull proportions, and relative gill raker length and spacing), we first calculated maximum likelihood estimates for all ancestral states with the 'geiger' package (Harmon et al. 2008) in R 2.11.1. Then, we calculated standardized changes along each branch by subtracting ancestral from descendant state value and divided this value by branch length of the segment. Trait change divided by time (branch length) is equal to rate of change. This approach is similar to a method developed by McPeek (1995).

In order to test for differences between the means of phylogenetic residuals and standardized changes of zooplanktivores and non-zooplanktivores, we performed Welch Two Sample $t$ tests and permutation tests (10,000 iterations). The permutation distribution results from repeated drawing of samples (with $\mathrm{n}$ equal to the number of zooplanktivores) from all observations (zooplanktivores and non-zooplanktivores). The difference of the means of the simulated zooplanktivores and non-zooplanktivores is calculated for all iterations. Then, the observed difference for the actual species is compared to the permutation distribution. We provide an approximate $P$ value (rounded to second decimal) for the permutation tests, because the $P$ values vary slightly for repeated tests. Both the $t$ test and permutation test ('DAAG' package; Maindonald and Braun 2009) were implemented in R.2.11.1.

\section{Results}

Scaling of eye dimensions

Eyeball diameter scales with negative allometry to body mass. The slope of the regression of the independent contrasts of eyeball diameter on contrasts of body mass is 0.26 , which is different from $0.33(P=0.021)$, the expected slope for isometry. The slope of the phylogenetically uninformed regression of eye diameter on body mass is not different from 0.33 (slope $=0.303$; Table 1; Fig. 3a).

We find similar patterns for ontogenetic scaling of eye diameter with body mass of zooplanktivores and their sister species (Fig. 3b-d). Regression slopes for C. parrae $($ slope $=0.22)$ vs. B. mesothorax $($ slope $=0.21)$ and C. solorensis $($ slope $=0.12)$ vs. $P$. evanidus $($ slope $=0.20)$ are not different. In contrast, eye diameter of $H$. pictus scales faster (slope $=0.32$ ) with body mass than eye diameter of $H$. bivittatus (slope $=0.19, P<0.001$ ).

Shape of the eye and its components (Table 1) scale isometrically with an increase in body size. The independent contrasts of axial length (slope $=1.025$ ), largest pupil diameter (slope $=0.994$ ), smallest pupil diameter 
Fig. 3 Scaling of eye diameter with body mass in labrids. a Plot of log-transformed eye diameter against logtransformed body mass of 21 labrid species. The other panels illustrate ontogenetic scaling of eye diameter with body mass: b Clepticus parrae (cp) and Bodianus mesothorax (bm), c Cirrhilabrus solorensis (cs) and Pseudocheilinus evanidus (pe), d Halichoeres pictus (hp) and Halichoeres bivittatus (hb). Regression slopes for $C$. parrae vs. B. mesothorax, and $C$. solorensis vs. P. evanidus are not different. In contrast, eye diameter of $H$. pictus scales faster with body mass than eye diameter of $H$. bivittatus. Gray circles are zooplanktivores, open circles non-planktivores
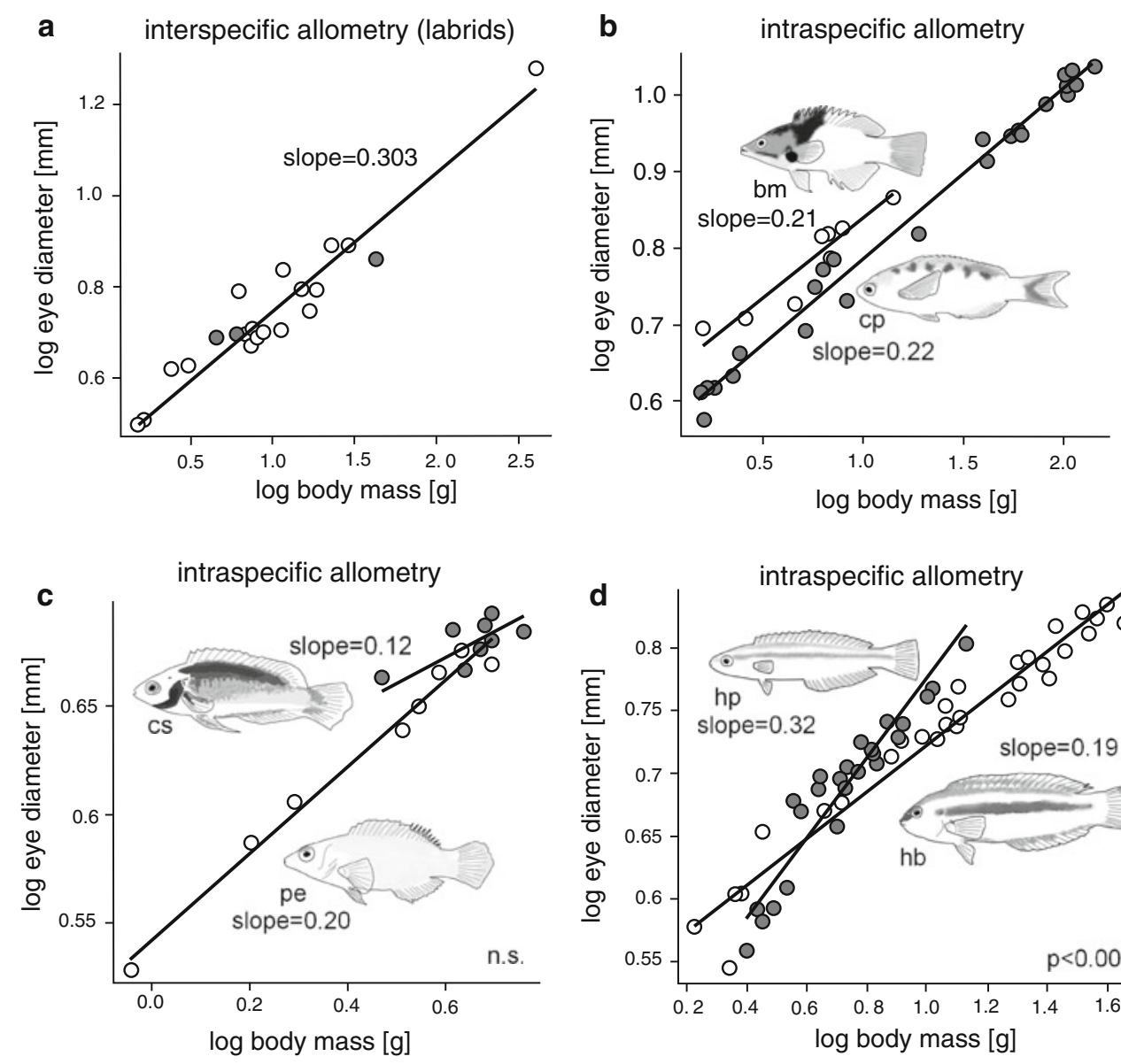

(slope $=1.043)$, and lens diameter $($ slope $=0.999)$ scale isometrically and are tightly correlated with contrasts of eyeball diameter ( $P$ value for slope $=0$ is smaller than 0.001 in all cases).

\section{Eye size}

Zooplanktivorous labrids do not have larger eyes than nonplanktivores. The histogram of the phylogenetic residuals of eye diameter on body size reveals that all three zooplanktivores are in the middle of the overall distribution of Labridae (Fig. 4a). We did not find differences between the means of zooplanktivore and non-planktivore residuals. Lachnolaimus maximus, a benthic forager on invertebrates, has the largest relative eye diameter, whereas $H$. bivittatus, another benthic forager, has the smallest.

Branches leading to zooplanktivorous labrids are not associated with large increases of relative eye diameter (Fig. 4b). The mean of the three zooplanktivore lineages analyzed in this study is not different from the remaining species. The changes associated with zooplanktivore branches are widely scattered throughout the labrid distribution. In fact, some of the largest increases and decreases in relative eyeball diameter appear on branches leading to zooplanktivorous species (H. pictus and $C$. parrae, respectively). Finally, the branch leading to $C$. solorensis has almost no change in relative eye diameter.

Lens size

Two of the three zooplanktivores (C. parrae and H. pictus) have the largest lenses relative to axial length among the labrids in this study. The residual of $C$. solorensis falls amidst the distribution of other labrids in the histogram of the phylogenetic residuals of lens diameter on axial length, and the mean of all zooplanktivore residuals is not different from the non-planktivores $(P=0.266)$. However, permutation tests yield a significant result $(P \sim 0.01$; we provide an approximate $P$ value for the permutation tests, because the $P$ values vary slightly for repeated tests).

Two of the three branches leading to zooplanktivores show large increases in relative lens size (Fig. 4c). The branches leading to H. pictus and C. parrae in fact have the largest and fourth largest changes of the entire labrid distribution. The second largest increase belongs to L. bicolor. The tip leading to $C$. solorensis features almost no change, and thus the mean of the changes associated with all three zooplanktivore branches is not different from all other 
Fig. 4 Summary of the findings on relative eyeball size, lens size, and head proportions in labrids. a Residuals of eye diameter on body size. b Standardized changes (i.e., point estimates of the magnitude of morphological evolution) in relative eye diameter. c Standardized changes in lens diameter relative to axial length. d Standardized changes in anterior facial area relative to orbit area. Gray bars are zooplanktivores, white bars non-zooplanktivores a eyeball diameter relative to body mass

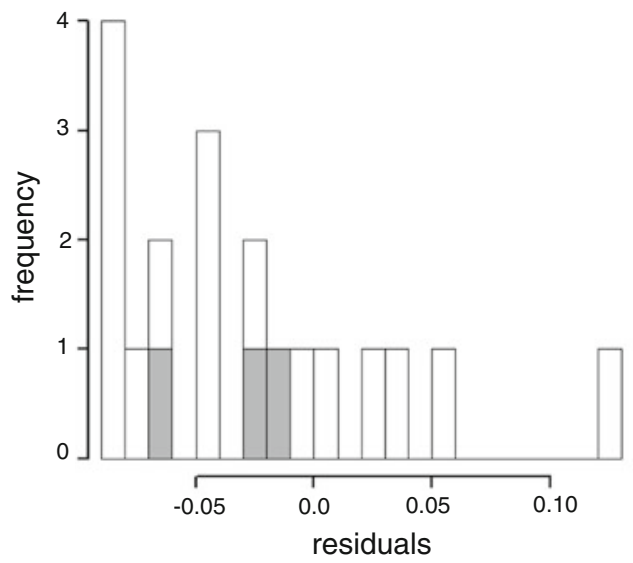

C lens diameter relative to axial length

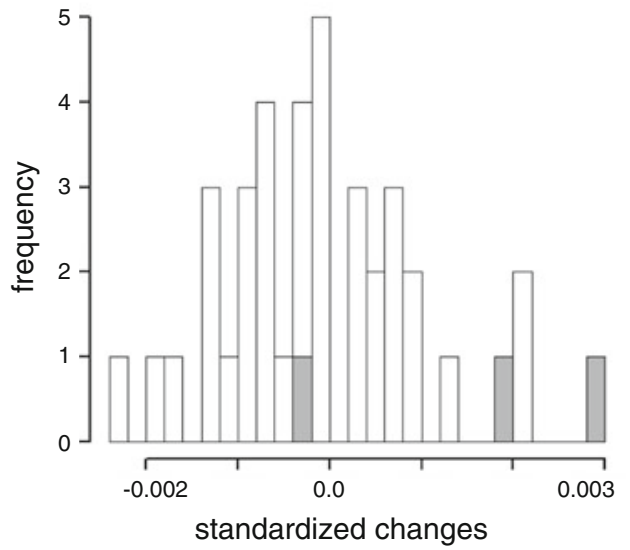

b eyeball diameter relative to body mass

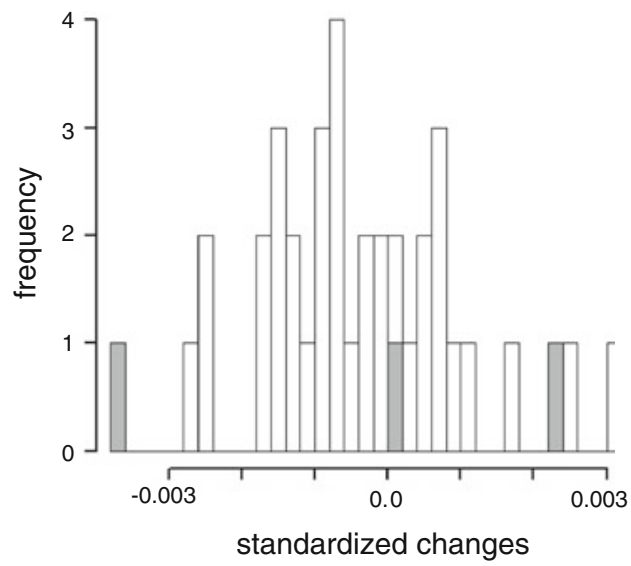

d anterior facial area relative to orbit area

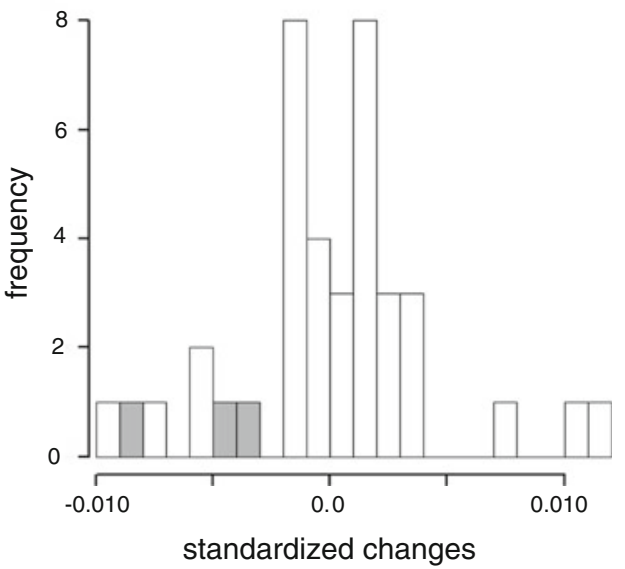

Table 4 Loadings on principal components (PC)

\begin{tabular}{lrrrrr}
\hline & PC1 & PC2 & PC3 & PC4 & PC5 \\
\hline Eye diameter (ED) & 0.99 & 0.12 & -0.05 & 0.05 & 0.05 \\
Axial length (AL) & 0.98 & 0.19 & 0.05 & -0.09 & -0.01 \\
Largest pupil diameter (PD1) & 0.98 & -0.11 & 0.14 & 0.06 & 0.00 \\
Smallest pupil diameter (PD2) & 0.97 & -0.22 & -0.06 & -0.07 & 0.01 \\
Lens diameter (LD) & 0.99 & 0.02 & -0.09 & 0.06 & -0.05 \\
Explained variance [\%] & 96.47 & 2.23 & 0.73 & 0.44 & 0.12 \\
\hline
\end{tabular}

branches $(P=0.1958)$. Again, permutation tests indicate overall significant differences of the means in planktivores and non-planktivores $(P \sim 0.01)$.

Skull proportions

We analyzed the size of the head and parts of the head in comparison to orbit size, a proxy for eye diameter (Table 2). Zooplanktivores may have shorter anterior facial length ( $t$ test, $P=0.099$ ) or a smaller anterior facial region ( $t$ test, $P=0.074$ ) than non-planktivorous labrids. The non-significance is potentially an effect of lack of power of the tests, as permutation tests indicate significant differences (anterior facial length: $P \sim 0.01$, anterior facial area: $P \sim 0.01)$. A stronger pattern emerges when comparing standardized changes: zooplanktivores have a large decrease in anterior facial region ( $t$ test, $P=0.051$, Fig. 4d) and anterior facial length ( $t$ test, $P=0.001$ ). Permutation tests yielded similar support (anterior facial region: $P \sim 0.02$, anterior facial length: $P \sim 0.03$ ).

Phylogenetic principal component analysis of eyeball dimensions

We performed a phylogenetically informed principal component analysis on the log-transformed eyeball variables (eye diameter, axial length, largest and smallest pupil diameter, and lens diameter). Eye shape is not very variable: principal component (PC) 1, a size axis, explains $96.47 \%$ of the variation in the data set (Table 4 ); $3.53 \%$ of the variation can be ascribed to variation in shape alone (PC 2: $2.23 \%$, PC 3: $0.73 \%$, PC 4: $0.44 \%$, PC 5: 0.12\%). PC 2 has negative loading on largest and smallest pupil 
diameter $(-0.11$ and -0.22 , respectively), and positive loading on eyeball diameter (0.12), axial length (0.19), and lens diameter (0.02), and thus we interpret PC 2 as a measure of relative pupil size. A small value for PC 2 translates into a relatively large pupil. PC 3 has positive loading on largest pupil diameter $(0.14)$ and negative loading on smallest pupil diameter $(-0.06)$ and lens diameter $(-0.09)$. Therefore, we tentatively interpret this shape axis as a measure of pupil ellipticity. A large value for PC 3 relates to a large and strongly elliptical pupil, in combination with a small lens diameter.

The plot of PC 3 against PC 2 demonstrates that two zooplanktivores, namely $C$. parrae and $H$. pictus, may occupy a different region of morphospace than other labrids (Fig. 5). Both species have low scores on PC 2 and especially PC 3. All three zooplanktivores, including C. solorensis, have much lower scores on PC3 than their sister species (B. mesothorax, P. evanidus, and H. bivittatus, respectively). In fact, the mean of zooplanktivore scores on PC3 is lower than for non-planktivores, as indicated by permutation tests $(P \sim 0.03)$, even though $C$. solorensis plots in the middle of the labrid distribution (Fig. 5). A similar result is found when standardized changes are

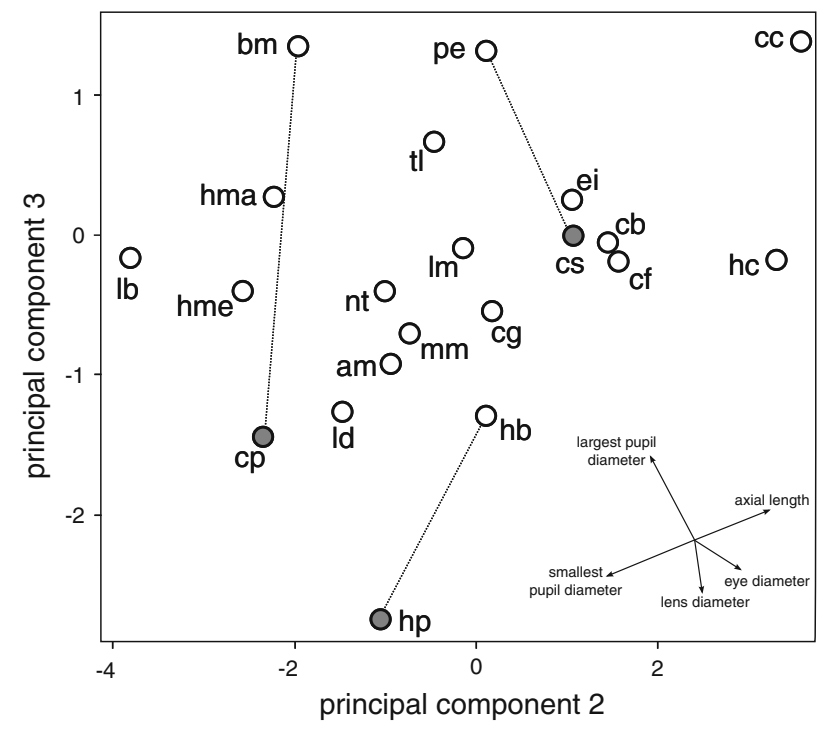

Fig. 5 Bivariate plot of principal components 2 and 3. Gray circles are zooplanktivores, open circles non-zooplanktivores. Zooplanktivores and their sister species are connected by dashed lines. The vector plot in the bottom right corner illustrates direction and magnitude of loadings of the variables on principal components 2 and 3. am Anampses meleagrides, bm Bodianus mesothorax, cb, Cetoscarus bicolor, cc Cheilinus chlorourus, cf Cheilinus fasciatus, cg Coris gaimard, cp Clepticus parrae, cs Cirrhilabrus solorensis, ei Epibulus insidiator, hb Halichoeres bivittatus, hc Halichoeres chloropterus, hma Halichoeres marginatus, hme Hemigymnus melapterus, $\mathrm{lb}$ Labroides bicolor, ld Labroides dimidiatus, Im Lachnolaimus maximus, mm Macropharyngodon meleagris, nt Novaculichthys taeniourus, pe Pseudocheilinus evanidus, tl Thalassoma lunare considered. Permutation tests point to differences between zooplanktivore transitions and others $(P \sim 0.01)$.

Cheilinus chlorourus, $C$. fasciatus, E. insidiator, and Cetoscarus bicolor have large scores for PC 2 (i.e., relatively small pupil), which may indicate that the clade composed of cheilines and scarines (Fig. 1) occupies a distinct area in eyeball morphospace. However, note that the julidine H. chloropterus also has a large score on PC 2 .

Size and density of gill rakers

Zooplanktivorous labrids may have longer gill rakers than others, but they are not spaced closer together, i.e., their density is not higher (Table 3). C. parrae and H. pictus have the largest and fourth largest relative gill raker length of all sampled labrids, whereas $C$. solorensis plots near the middle of the distribution. The mean of the zooplanktivore residuals is not different from the mean of other labrids ( $t$ test, $P=0.22$ ). Permutation tests yielded better support $(P \sim 0.01)$.

However, we observe a stronger pattern when comparing the standardized changes in relative gill raker length. The branches leading to $C$. parrae and $H$. pictus display large increases in length, whereas the branch leading to $C$. solorensis features an intermediate increase (Fig. 6). The mean of all three changes associated with zooplanktivore lineages is different from that of all non-planktivores ( $t$ test, $P=0.048$; permutation tests $P \sim 0.01$ ).

The density of gill rakers does not differ between zooplanktivores and non-planktivores, whether examining residuals or standardized changes.

gill raker length relative to body mass

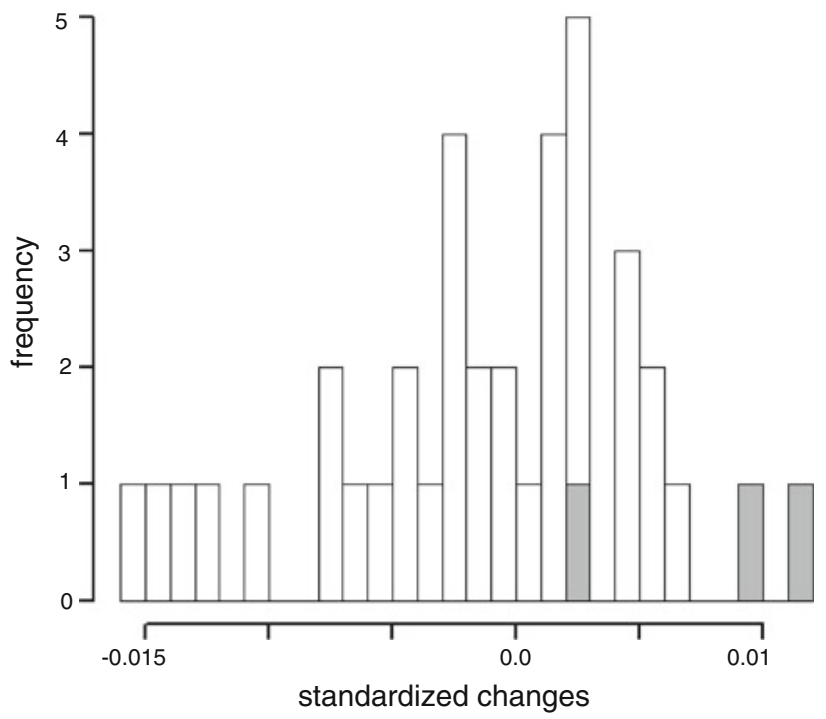

Fig. 6 Histogram of the standardized changes in gill raker length relative to body mass. Gray bars are zooplanktivores, white bars nonzooplanktivores 


\section{Discussion}

Zooplanktivory evolved repeatedly during the latest phase of trophic innovations in labrid fishes (Cowman et al. 2009), and we tested whether transitions to this highly specialized feeding mode are linked with changes in morphology of the eye and skull. We found little support for the hypothesis that zooplanktivorous labrids have bigger eyes. However, two of the three zooplanktivores (C. parrae and $H$. pictus) show a suite of other morphological features that may reflect higher visual acuity (larger lens) and improved handling of zooplankton (longer gill rakers). The third zooplanktivore $(C$. solorensis) lacks all predicted adaptations for zooplanktivory.

The large-eye hypothesis was posed under the assumption that different feeding types require different visual abilities (Walls 1942). Highly selective visual foragers such as planktivores feeding on small prey may need better visual performance than visually non-selective foragers such as herbivores or detritivores. In fact, it is difficult to rank species according to their need for visual acuity. Zooplanktivores are expected to have excellent visual acuity because they feed on small, quickly drifting organisms with low contrast to their background (Johnsen 2001). The food items of other species are generally believed to be easier to detect than zooplankton. However, most labrids appear to use strong visual acuity in their feeding behavior, many to detect small animal prey, the ancestral feeding mode of labrids (Cowman et al. 2009). One potential explanation for the absence of larger eyes in zooplanktivorous labrids is that feeding in most labrids involves detecting small prey in a complex habitat, and thus, most labrids experience strong selection on visual acuity. The difficulty with this explanation is that the zooplanktivores in our study do show other predicted modifications of the eyes that are consistent with enhanced visual acuity.

Our inability to find evidence of larger eyes in zooplanktivores is slightly complicated by differences between species in the ontogenetic scaling of eye diameter. We compared regression slopes of the three zooplanktivores and their closest relatives in our analysis. The slopes of two species pairs $(C$. parrae and $B$. mesothorax; $C$. solorensis and $P$. evanidus) are the same, and thus comparisons of relative size are independent from body mass of the examined specimens. A more complex result is found in $H$. pictus and $H$. bivittatus. Eye diameter of $H$. pictus increases faster with body mass than in the non-planktivore $H$. bivittatus. Very small individuals of $H$. pictus have smaller eyes than $H$. bivittatus, whereas very large specimens of $H$. pictus have larger eyes. Thus, the difference in eye diameter between these species is body size specific. Our samples of $H$. pictus ranged from terminal phase males to small but reproductive initial phase fish.
We found evidence that transitions to zooplanktivory have influenced the evolution of eye shape. The size of the lens compared to the axial length of the eye was markedly enlarged in two of three sampled zooplanktivore lineages (C. parrae and $H$. pictus), confirming the prediction from physiological optics. In contrast, the relative size of the lens of $C$. solorensis was average for labrids. The lineage to L. bicolor is characterized by the second largest increase of relative lens size within labrids. L. bicolor feeds on smallsized parasites on other fish and thus could potentially benefit from high visual acuity as well. The lineage to L. dimidiatus, also an ectoparasite feeder, does not show a large increase, however, so the adaptive significance of an enlarged lens in L. bicolor is ambiguous.

Pupil shape also was associated with shifts to zooplanktivory, in combination with large lens size. In particular, C. parrae and H. pictus have lower scores on PC 3, indicating a round pupil combined with a large lens. C. solorensis has average scores on PC 3 although the pupil is rounder than its close relative, P. evanidus. Pupil shape is not directly related to visual acuity, yet is important for focusing on nearby objects. A strongly elliptical pupil correlates with the aphakic gap, in which the lens can be moved to focus on close objects in that direction (Sivak 1978; Fernald and Wright 1985). Zooplanktivores search the water column for prey, and their area of visual interest is not confined to a narrow frontal field. Thus, their particularly round pupil shape may represent an adaptation to search a three-dimensional body of water for food. To our knowledge, this is the first report of increases in lens size and pupil roundness in association with zooplanktivory.

Zooplanktivorous labrids had longer gill rakers than the other species, supporting the prediction from functional morphology, yet they did not have more closely packed gill rakers. It is interesting that the increase of relative gill raker length in $C$. solorensis is minimal, similar to the pattern we observed regarding relative lens size and PC 3. Species of Cirrhilabrus are considered to be typical zooplanktivores, feeding in the open water above coral reefs where they visually pick plankton. In addition, their gut contents were found to consist almost exclusively of zooplankton (Gerber and Marshall 1974). The Cirrhilabrus group has been shown to exhibit locomotor adaptations for the midwater habitat (Wainwright et al. 2002) and musculoskeletal modifications of the jaws consistent with feeding on zooplankton (Wainwright et al. 2004). However, Cirrhilabrus lacks long gill rakers and other potential zooplanktivore adaptations such as large lenses and round pupils. A possible visual adaptation of Cirrhilabrus is the presence of a divided pupil, which has been hypothesized to function as a 'magnifier' to detect small prey (Baensch and Debelius 1994). The optical significance of the divided pupil is unknown, and thus this 
hypothesis cannot be tested at this point. The divided cornea is also present in the zooplanktivorous Paracheilinus but also in the benthic foragers Pseudocheilinus, Pseudocheilinops, and Pteragogus (Randall and Lubbock 1981). Hence, this feature may not be an adaptation to zooplanktivory in a strict sense. A final possibility is that Cirrhilabrus species are not the exclusive zooplanktivores that they are often portrayed to be. We have observed that Cirrhilabrus caught in the wild often have considerable amounts of amorphous organic matter in their guts, consistent with consumption of marine snow and other aggregations of detritus and microbes. Perhaps long gill rakers would hinder handling of detritus, tending to become entangled in it.

Comparative analyses of eye diameter in transitions to zooplanktivory can potentially be confounded with the influence of water depth and nocturnality, both of which expose the organism to low light levels (Lythgoe 1979). Nocturnal and mesopelagic fish tend to have relatively large eyes (Marshall 1979; Warrant 2004; Warrant and Locket 2004), a pattern supported in recent quantitative analyses (Ingram and Shurin 2009; Goatley and Bellwood 2009). The visual environment of labrids is characterized by clear, well-illuminated ocean waters, since most species inhabit tropical reefs (Lythgoe 1979). Labrids are diurnal (Randall 1967) and occur in the photic zone (Randall 1983, 2005; Westneat and Alfaro 2005). Some species, for example Bodianus ssp. (Weitkamp and Sullivan 1939; Gomon 2001, 2006; Mundy 2005) and Cirrhilabrus bathyphilus (Randall and Nagareda 2002), may also migrate into deeper waters characterized by dim light, but do not seem to consistently inhabit this zone. None of the species that we investigated occur in deep-water. Light levels may also vary with microhabitat. For example, reef crevices, caves, and areas of dense coral rubble are less illuminated than other parts of the reef. It is possible that species specializing on these dark microhabitats have large eyes. Yet in all, light levels are unlikely to have a major influence on the evolution of eyeball morphology in labrids.

Although a number of previous studies have concluded that zooplanktivores have enlarged eyes (McPhail 1984; Strauss 1984; Baumgartner et al. 1988; Pankhurst 1989; Hulsey et al. 2007; Cooper and Westneat 2009; Goatley and Bellwood, 2009), at least one previous analysis of Sebastes rockfishes did not (Ingram and Shurin 2009). It appears then that enlarged eyes are not a universal adaptive visual specialization of zooplanktivores. Perhaps this should not be too surprising as convergent evolution virtually never produces identical phenotypes, both because the ancestral phenotype affects the response to selection and because in complex systems there can be multiple solutions to the same functional challenge. We did find modifications of labrid eye shape that are consistent with an increase in visual performance during transitions to planktivory, but these measurements have not been reported yet in other groups, so their generality is unknown. It remains a goal of future research to determine the phylogenetic consistency of the evolutionary response of the visual system in coral reef zooplanktivores.

Our inability to find strong evidence of enlarged eyes in zooplanktivores coupled with the finding that these species have reduced facial structures suggests that the combination of these traits may give the impression of larger eyes. We feel that this result should raise a cautionary note about the patterns that have been reported in other groups. While some studies have shown that zooplanktivores have larger eyes relative to body size (e.g., McPhail 1984; Goatley and Bellwood 2009), other studies either report eye diameter changes relative to head length (Hulsey et al. 2007) or only include eye diameter as part of a larger multivariate construct (Strauss 1984; Cooper and Westneat 2009). Few studies account for phylogeny in their analyses.

Visual performance is a classically complex functional system, being an integrated result of multiple underlying components, including optics, retina, and neurology. In addition to the traits addressed in this study, visual performance of zooplanktivores may also be associated with ganglion cell densities (e.g., Collin and Pettigrew1989) and sensitivity to ultraviolet light (Siebeck and Marshall 2007). Other examples of the potential for diversity in response to visual performance include work with larval reef fishes in which light sensitivity changes throughout early ontogeny independent of eye shape (Job and Bellwood 2000), indicating that other components of the visual system were modified. We predicted morphological changes to improve acuity based on physiological optics, assuming that the retina and neurological mechanism are the same. It seems clear that there is potential for diversity in the response of different lineages to the challenges of zooplanktivory. To conclude, it will be important to repeat this study on other groups of fishes, addressing multiple components of the visual system. Such analyses will provide us with a more integrative understanding of the evolution of the visual system in response to evolutionary transitions to zooplanktivory.

Acknowledgments We thank S. Price and C. Martin for improving earlier versions of this manuscript. R. Holzman and M. McGee provided helpful comments during the project. D. Bellwood and two anonymous reviewers improved the manuscript with valuable suggestions. LS was supported by a postdoctoral fellowship of the Deutsche Forschungsgemeinschaft (DFG). Funding for the specimens and laboratory work was provided by National Science Foundation grant IOS-0924489 to PCW.

Open Access This article is distributed under the terms of the Creative Commons Attribution Noncommercial License which permits any noncommercial use, distribution, and reproduction in any medium, provided the original author(s) and source are credited. 


\section{References}

Alfaro M, Brock CD, Banbury B, Wainwright PC (2009) Does evolutionary innovation in pharyngeal jaws lead to rapid lineage diversification in labrid fishes? BMC Evol Biol 9:255

Baensch HA, Debelius H (1994) Baensch marine atlas, volume 1. Microcosm, Shelburne

Barel CDN (1982) Towards a constructional morphology of cichlid fishes. Neth J Zool 33:357-424

Baumgartner HA, Bell MA, Weiberg PH (1988) Body form differences between the Enos Lake species pair of threespine sticklebacks (Gasterosteus aculeatus complex). Can J Zool 66:467-474

Blomberg SP, Garland T Jr, Ives AR (2003) Testing for phylogenetic signal in comparative data: behavioral traits are more liable. Evolution 57:717-745

Collin SP, Pettigrew JD (1989) Quantitative comparison of the limits of visual spatial resolution set by the ganglion cell layer in twelve species of reef teleosts. Brain Behav Evol 34:184-192

Cooper WJ, Westneat MW (2009) Form and function of damselfish skulls: rapid and repeated evolution into a limited number of trophic niches. BMC Evol Biol 9:24

Cowman, Bellwood DR, van Herwerden L (2009) Dating the evolutionary origins of wrasse lineages (Labridae) and the rise of trophic novelty on coral reefs. Mol Phylogenet Evol 52:621-631

Davis WP, Birdsong RS (1973) Coral reef fishes which forage in the water column. Helgol Wiss Meeresunters 24:292-306

Douglas RH, Hawryshyn CW (1990) Behavioral studies of fish vision: an analysis of visual capabilities. In: Douglas $\mathrm{RH}$, Djamgoz MBA (eds) The visual system of fish. Chapman and Hall, London, pp 373-418

Drenner RW, Mummert JR, deNoyelles F Jr, Kettle D (1984) Selective particle ingestion by a filter-feeding fish and its impact on phytoplankton community structure. Limnol Oceanogr 29: 941-948

Dullemeijer P, Barel CDN (1977) Functional morphology and evolution. In: Hecht M, Goody P, Hecht B (eds) Major patterns in vertebrate evolution. NATO Adv Study Inst Ser A 14, pp 83-117

Felsenstein J (1985) Phylogenies and the comparative method. Am Nat 125:1-15

Fernald RD (1990) The optical system of fishes. In: Douglas RH, Djamgoz MBA (eds) The visual system of fish. Chapman and Hall, London, pp 45-62

Fernald RD, Wright SE (1985) Growth of the visual system in the African cichlid fish, Haplochromis burtoni. Vision Res 25:163-170

Fryer G, Iles TD (1972) The cichlid fishes of the Great Lakes of Africa: their biology and evolution. Oliver and Boyd, Edinburgh

Gerber RP, Marshall N (1974) Ingestion of detritus by the lagoon pelagic community at Eniwetok Atoll. Limnol Oceanogr $19: 815-824$

Goatley CHR, Bellwood D (2009) Morphological structure in a reef fish assemblage. Coral Reefs 28:449-457

Gomon MF (2001) Descriptions of two new species of Bodianus (Perciformes: Labridae) from Australasian waters. N Z J Zool 28:407-416

Gomon MF (2006) A revision of the labrid fish genus Bodianus with descriptions of eight new species. Rec Aust Mus Suppl 30:1-133

Hairston NG, Li KT, Easter SS (1982) Fish vision and the detection of planktonic prey. Science 218:1240-1242

Harmon LJ, Weir JT, Brock CD, Glor RE, Challenger W (2008) GEIGER: investigating evolutionary radiations. Bioinformatics 24:129-131
Hart PJB, Gill AB (1994) Evolution of foraging behavior in the threespine stickleback. In: Bell MA, Foster SA (eds) The evolutionary biology of the threespine stickleback. Oxford University Press, Oxford

Hobson ES (1991) Trophic relationships of fishes specialized to feed on zooplankters above coral reefs. In: Sale PF (ed) The ecology of fishes on coral reefs. Academic Press, San Diego, pp 69-95

Hobson ES, Chess JR (1976) Trophic interactions among fishes and zooplankters nearshore at Santa Catalina Island, California. Fish Bull 74:567-598

Hobson ES, Chess JR (1978) Trophic relationships among fishes and plankton in the lagoon at Enewetak Atoll, Marshall Islands. Fish Bull 76:133-153

Hughes A (1977) The topography of vision in mammals of contrasting life style: comparative optics and retinal organisation. In: Crescitelli $F$ (ed) The visual system in vertebrates. Springer-Verlag, Berlin, Heidelberg, New York, pp 613-756

Hulsey CD, Mims MC, Streelman JT (2007) Do constructional constraints influence cichlid craniofacial diversification? Proc $\mathrm{R}$ Soc B 274:1867-1875

Hung GK, Ciuffreda KJ (2002) Models of the visual system. Springer, Berlin, Heidelberg, New York

Ingram T, Shurin JB (2009) Trait-based assembly and phylogenetic structure in northeast Pacific rockfish assemblage. Ecology 90:2444-2453

Job SD, Bellwood DR (2000) Light sensitivity in larval fishes: implications for vertical zonation in the pelagic zone. Limnol Oceanogr 45:362-371

Johnsen S (2001) Hidden in plain sight: the ecology and physiology of organismal transparency. Biol Bull 201:301-318

Kassam DD, Adams DC, Ambali AJD, Yamaoka K (2003) Body shape variation in relation to resource partitioning within cichlid trophic guilds coexisting along the rocky shore of Lake Malawi. Anim Biol 53:59-70

Kazancioğlu E, Near TJ, Hanel R, Wainwright PC (2009) Influence of sexual selection and feeding functional morphology on diversification rate of parrotfishes (Scaridae). Proc R Soc, B 276:3439-3446

Kiltie RA (2000) Scaling of visual acuity with body size in mammals and birds. Funct Ecol 14:226-234

Kröger RHH, Fritsches KA, Warrant EJ (2009) Lens optical properties in the eyes of large marine predatory teleosts. J Comp Physiol A 195:175-182

Land MF (1981) Optics and vision in invertebrates. In: Land MF, Laughlin SB, Naessel DR, Strausfeld NJ, Waterman TH (eds) Comparative physiology and evolution of vision in invertebrates B: invertebrate visual centers and behavior I. Springer-Verlag, Berlin, Heidelberg, New York, pp 471-592

Land MF, Nilsson D-E (2002) Animal eyes. Oxford University Press, Oxford

Langeland A, Nøst T (1995) Gill raker structure and selective predation on zooplankton by particulate feeding fish. J Fish Biol 47:719-732

Langerhans RB, Layman CA, Langerhans AK, Dewitt TJ (2003) Habitat-associated morphological divergence in two Neotropical fish species. Biol J Linn Soc 80:689-698

Loew ER, McFarland WN (1990) The underwater visual environment. In: Douglas RH, Djamgoz MBA (eds) The visual system of fish. Chapman and Hall, London, pp 1-43

Lythgoe JN (1979) The ecology of vision. Clarendon Press, Oxford

Magnuson JJ, Heitz JG (1971) Gill raker apparatus and food selectivity among mackerels, tunas, and dolphins. Fish Bull 69:361-370

Maindonald J, Braun WJ (2009) DAAG: data analysis and graphics data and functions. $\mathrm{R}$ package version 1.01. http://CRAN.Rproject.org/package $=$ DAAG 
Marshall NB (1979) Developments in deep-sea biology. Blandford Press, Poole, Dorset

McPeek MA (1995) Testing hypotheses about evolutionary change on single branches of a phylogeny using evolutionary contrasts. Am Nat 145:686-703

McPhail JD (1984) Ecology and evolution of sympatric sticklebacks (Gasterosteus): morphological and genetic evidence for a species pair in Enos Lake, British Columbia. Can J Zool 62:14021408

Miller WH (1979) Intraocular filters. In: Autrum H (ed) Comparative physiology and evolution of vision in invertebrates A: invertebrate photoreceptors. Springer-Verlag, Berlin, Heidelberg, New York, pp 69-143

Motta PJ (1988) Functional morphology of the feeding apparatus of ten species of Pacific butterflyfishes (Perciformes, Chaetodontidae): an ecomorphological approach. Environ Biol Fish 22: $39-67$

Mundy BC (2005) Checklist of the fishes of the Hawaiian Archipelago. Bishop Mus Bull Zool 6:1-704

Pankhurst NW (1989) The relationship of ocular morphology to feeding modes and activity periods in shallow marine teleosts from New Zealand. Environ Biol Fishes 26:201-211

Paradis E, Claude J, Strimmer K (2004) APE: analyses of phylogenetics and evolution in R language. Bioinformatics 20:289-290

Parenti P, Randall JE (2000) An annotated checklist of the species of the labroid fish families Labridae and Scaridae. Ichthyol Bull JLB Smith Inst Ichthyol 68:1-97

R Development Core Team (2010) R: A language and environment for statistical computing. $\mathrm{R}$ foundation for statistical computing, Vienna, Austria. ISBN 3-900051-07-0, URL http://www.Rproject.org

Randall JE (1967) Food habits of reef fishes of the West Indies. Stud Trop Oceanogr 5:655-847

Randall JE (1983) Caribbean reef fishes. TFH Publications, Neptune City, NJ

Randall JE (2005) Reef and shore fishes of the South Pacific. University of Hawaii Press, Honolulu

Randall JE, Lubbock R (1981) Labrid fishes of the genus Paracheilinus, with descriptions of three new species from the Philippines. Jpn J Ichthyol 28:19-30

Randall JE, Nagareda BH (2002) Cirrhilabrus bathyphilus, a new deepdwelling labrid fish from the Coral Sea. Cybium 26:123-127

Revell LJ (2009) Size-correction and principal components for interspecific comparative studies. Evolution 63:3258-3268

Robinson BW, Parsons KJ (2002) Changing times, spaces and faces: tests and implications of adaptive morphological plasticity in the fishes of northern postglacial lakes. Can J Fish Aquat Sci 59: $1819-1833$

Schluter D (1993) Adaptive radiation in sticklebacks: size, shape and habitat use efficiency. Ecology 74:699-709

Schmitz L (2009) Quantitative estimates of visual performance features in fossil birds. J Morph 270:759-773

Schmitz L, Motani R (2010) Morphological differences between the eyeballs of nocturnal and diurnal amniotes revisited from optical perspectives of visual environments. Vision Res 50:936946

Siebeck UE, Marshall NJ (2007) Potential ultraviolet vision in presettlement larvae and settled reef fish-a comparison across 23 families. Vision Res 47:2337-2352

Sivak JG (1978) The functional significance of the aphakic space of the fish eye. Can J Zool 56:513-516

Sivak JG (1990) Optical variability in the fish lens. In: Douglas RH, Djamgoz MBA (eds) The visual system of fish. Chapman and Hall, London, pp 63-108

Strauss RE (1984) Allometry and functional feeding morphology in haplochromine cichlids. In: Echelle AA, Kornfield I (eds) Evolution of fish species flocks. Univ Maine Press, ME, pp 217-230

Wainwright PC (1988) Morphology and ecology: the functional basis of feeding constraints in Caribbean labrid fishes. Ecology 69:635-645

Wainwright PC, Bellwood DR (2002) Ecomorphology of feeding in coral reef fishes. In: Sale PF (ed) Coral reef fishes. Dynamics and diversity in a complex ecosystem. Academic Press, San Diego, pp 33-55

Wainwright PC, Richard BA (1995) Predicting patterns of prey use from morphology of fishes. Env Biol Fish 44:97-113

Wainwright PC, Bellwood DR, Westneat MW (2002) Ecomorphology of locomotion in labrid fishes. Environ Biol Fish 65:47-62

Wainwright PC, Bellwood DR, Westneat MW, Grubich JR, Hoey AS (2004) A functional morphospace for the skull of labrid fishes: patterns of diversity in a complex biomechanical system. Biol J Linn Soc 82:1-25

Walls GL (1942) The vertebrate eye and its adaptive radiation. Hafner Pub Co, New York

Warrant EJ (2004) Vision in the dimmest habitats on earth. J Comp Physiol A 190:765-789

Warrant EJ, Locket NA (2004) Vision in the dep sea. Biol Rev 79: 671-712

Warton D, and translated to R by Ormerod J (2007). smatr: (standardised) major axis estimation and testing routines. $\mathrm{R}$ package version 2.1. http://web.maths.unsw.edu.au/ dwarton

Warton DI, Wright IJ, Falster DS, Westoby M (2006) Bivariate linefitting methods for allometry. Biol Rev 81:259-291

Weitkamp DE, Sullivan RD (1939) Fishes. The John Murray expedition 1933-1934. Sci Rep John Murray Exped 7:1-116

Westneat MW (1995) Feeding, function, and phylogeny: analysis of historical biomechanics in labrid fishes using comparative methods. Syst Biol 44:361-383

Westneat MW, Alfaro ME (2005) Phylogenetic relationships and evolutionary history of the reef fish family Labridae. Mol Phylogenet Evol 36:370-390

Westneat MW, Alfaro ME, Wainwright PC, Bellwood DR, Grubich JR, Fessler J, Clements KD, Smith L (2005) Repeated convergence of skull biomechanics in coral reef fishes. Proc R Soc B 272:993-1000 